\title{
Analysis of the production of salmon fillet - Prediction of production yield
}

Johansson, Gine Ørnholt; Guðjónsdóttir, María; Nielsen, Michael Engelbrecht; Skytte, Jacob Lercke; Frosch, Stina

Published in:

Journal of Food Engineering

Link to article, DOI:

10.1016/j.jfoodeng.2017.02.022

Publication date:

2017

Document Version

Peer reviewed version

Link back to DTU Orbit

Citation (APA):

Johansson, G. Ø., Guð̌jónsdóttir, M., Nielsen, M. E., Skytte, J. L., \& Frosch, S. (2017). Analysis of the production of salmon fillet - Prediction of production yield. Journal of Food Engineering, 204, 80-87.

https://doi.org/10.1016/j.jfoodeng.2017.02.022

\section{General rights}

Copyright and moral rights for the publications made accessible in the public portal are retained by the authors and/or other copyright owners and it is a condition of accessing publications that users recognise and abide by the legal requirements associated with these rights.

- Users may download and print one copy of any publication from the public portal for the purpose of private study or research.

- You may not further distribute the material or use it for any profit-making activity or commercial gain

- You may freely distribute the URL identifying the publication in the public portal

If you believe that this document breaches copyright please contact us providing details, and we will remove access to the work immediately and investigate your claim 


\title{
Analysis of the production of salmon fillet - prediction of production yield
}

\author{
Gine Ørnholt-Johansson ${ }^{*}$, María Gudjónsdóttirb, Michael Engelbrecht Nielsenc, Jacob Lercke \\ Skyttea, Stina Froscha
}

aDivision for Food Technology, Research Group for Food Production Engineering, National Food Institute, Technical University of Denmark, Søltofts Plads 248, DK-2800 Kgs. Lyngby, Denmark. *Corresponding author: gijo@food.dtu.dk, telephone: +45 2263 61 62, fax: +45 35886341

b University of Iceland, Faculty of Food Science and Nutrition, Vínlandsleid 14, 113 Reykjavík, Iceland. c Fast-Q, R\&D, Sagasvej 2A, 1861 Frederiksberg, Denmark

\section{Abstract}

The aim was to investigate the influence of raw material variation in Atlantic salmon from aquaculture on filleting yield, and to develop a decision tool for choosing the appropriate raw material for optimized yield. This was achieved by tracking salmon on an individual level $(n=60)$ through a primary production site. The majority of the salmon exhibited a heavier right fillet compared to the left fillet after filleting. No explicit explanation was found for this observation although the heading procedure was shown to have a large impact. A Partial Least Square model was built to predict the yield after filleting. The model was based on six preprocessing variables and allowed an acceptable prediction of the filleting yield with a root mean square error cross validation of 0.68 . The presented model can estimate the slaughter yield for a certain batch before ordering from the slaughterhouse. This may facilitate optimal planning of the production of salmon fillets by ordering and assigning the right batch to the right product category to obtain an optimal yield and quality.

Keywords: Production analysis; Prediction; Atlantic salmon; Yield; Multivariate data analysis; PLS

\section{Introduction}

Due to the growing population in the World, an increase in food demand of around $70 \%$ by 2050 is foreseen (Searchinger et al. 2013). This provides the food industry with a strong incitement to increase product yield in a cost-effective manner (Somsen et al. 2004). Food products are highly complex biological matrices with a combination of chemical and physical factors, which all together define the product characteristics (Rahman, 2005). The inherent variation in these factors, such as fat, protein and size, results in a natural raw material variation that influences the processing of the product. Moreover, the most valuable part of the salmon is the fillet hence increasing the overall exploitation of the salmon meat with focus on optimizing the yield of the fillets is desirable (Powell et al. 2008).

A structured approach to increase production yield may identify undesirable mass loss or areas in the production that allow for adjustment prior to processing (Somsen et al. 2004). Somsen et al. (2004) implemented a production yield analysis (PYA) method to identify areas in a poultry processing company where optimization in yield could take place by calculating the yield 
efficiency of the transformation process. Ineffective operating machinery and fine-tuning of machinery were just two of the actions that were identified. In contrast to PYA, which is focused on process steps and where they can be improved, process analytical technology (PAT) is aimed at monitoring the product throughout the production. To ensure the desired quality of the final product, PAT has long been used in the pharmaceutical industry and the methods have also been adapted to the food industry (Chew \& Sharratt, 2010; Pomerantsev \& Rodionova, 2012; van den Berg et al. 2013). PAT focuses on control using real-time monitoring that allows for modifications during production in case the indicators of the desired quality do not fulfil specified requirements (van den Berg et al. 2013). Instead of only applying post-production quality testing, it is beneficial to investigate the raw material properties and process variables during the production. This allows for adaption of the processing parameters in real time, which ensures the selected quality traits for the final product (Pomerantsev \& Rodionova, 2012). The two methods clearly have specific advantages when applied separately. Yet, a combination of them will provide the food producer with a valuable tool to first analyse the production, considering both process and biological variation of the raw material, and secondly, couple these findings to identify the processability of the product.

The processing of Atlantic salmon (Salmo salar) from aquaculture into fillets was used as case in this study. Aquaculture production of Atlantic salmon consists of a rearing period (24 to 36 months), including harvesting, slaughtering and gutting, all handling and transportation, before entering the primary processing. The primary processing encompasses the production of fillets or portions, either fresh or frozen (Melberg \& Davidrajuh, 2009). This study comprises an analysis of the production using PYA in order to identify areas where PAT can be applied in a future production situation. The hypothesis is that, by combining the ideas behind PYA and PAT, the characteristics of the incoming raw materials can be considered when planning, and also monitoring, the processes to subsequently enable a yield increase.

The aim of this study was therefore to investigate if comprehensive collection and analysis of data from processing companies could be utilized to increase the production yield in the salmon industry. To secure comprehensive data and traceability, each salmon entering the processing plant were followed on an individual level through the process. Thus, possible influences of biological variation in the raw material on the subsequent production yield could be revealed.

\section{Material and methods}

\subsection{Sampling}

Atlantic salmon (Salmo salar) $(\mathrm{n}=60)$ from three different slaughterhouses $(1,2$ and 3$)$ in Norway was used for the experiment. The salmon were all in the weight class from 4-5 kg and classified as SUPERIOR ${ }^{a}$ with respect to their quality. In January 2015, the salmon were harvested, iced and transported by truck to the production facilities of the participating company in the northern part of Denmark.

a The quality grade SUPERIOR represents salmon with no considerable defects such as damaged skin and significant loss of scales. They must be void of bruises, damaged belly or musculature (Regulation (EU) No 1151/2012). 
80

81

Table 1

Figure 1

All salmon were tagged in the mouth with an individually numbered pit tag. This was done to ensure tracking of the fish during processing and to later distinguish the heads. Images of all salmon were taken to enable objective evaluation of the belly cut. The salmon were held by the gills, hanging straight down, and a RedGreenBlue (RGB) image was taken with a digital camera. The weight (W), length (L) and thickness (T) across the dorsal fin of each fish were recorded. The processing line used for the study was from BAADER Food Processing Machinery (Nordischer Maschinenbau Rud Baader GmbH+Co KG, Lübeck, Germany). The gutted salmon were headed using the U-Cut heading machine for salmon (BAADER 434 S), filleted (P1) on a high speed filleting machine (BAADER 581), auto-trimmed (P2) on a high speed trimming machine (BAADER 988) and finally manually trimmed (P3) by well trained staff at the processing company. The salmon were placed consecutively on the production line for heading. Heads and tails were cut and the heads were collected for weighing and further analysis. The salmon were filleted mechanically and then collected, numbered and weighed after each processing step P1-P3.

\subsection{Data acquisition}

The heads were packed on ice in polystyrene boxes and transported to the Technical University of Denmark (DTU) in order to investigate the head cut. Each head was weighed on a Kern FCB scale (Kern \& Sohn $\mathrm{CmbH}$ ) with a weighing range of $8 \mathrm{~kg}$ and a readability of $0.1 \mathrm{~g}$. The heads were placed upside down in a beaker and a photo was taken with a digital camera in a specially designed white painted box (size $1150 \times 760 \times 800 \mathrm{~mm}$ ) with $20 \mathrm{~m}$ LED light bands (5000K, 390 Lumens, ClimaCare.dk) placed in a spiral along the sides (longitudinal direction) with approximately 10-15 cm between each winding in order to create a diffuse light. Images of the heads were investigated by a panel of four with respect to the presence of additional meat on either left or right side. Figure 1a presents an example of one of the head cuts where the presence of additional meat on the left side, marked by a circle, was unmistakable. The images of the belly cut were quantitatively analysed and ranked based on how big an arch the cut displayed. The ranking was made as presented in Figure 1b.

Based on the measured values of weight $(\mathrm{g})$, length $(\mathrm{cm})$ and thickness $(\mathrm{cm})$ a range of variables were calculated, and their definitions are presented in Table 1. 
116 The groupings of variables were chosen based on their use as normal evaluation criteria, their

117 availability (simple to measure), and because they hypothetically could have an influence on the

118 final yield.

119 Yield was calculated as the weight of the two fillets divided by the weight of the whole gutted

120 salmon and multiplied by $100 \%$.

\subsection{Statistics}

123 Data were statistically analysed using the Prism 6 (GraphPad Software, Inc., La Jolla, CA, USA) software for Mac. A paired t-test was used to test whether there was a significant size difference between the left and right fillets. The significance level was set to $P<0.05$. The influence of the gutted weight, length, thickness, degree of belly cut and $\mathrm{K}$ factor on the size difference between the left and right fillet were tested using ANOVA in the open-source software for statistical calculations, R (R Foundation for Statistical Computing, Vienna, Austria).

\subsection{Multivariate data analysis}

To establish the relationship between the main variables related to physical appearance and percentagewise yield, Partial Least Squares regression analysis (PLS) (Wold, 1975) was used to build a model for the prediction of yield. All models were built with the measured variables as the $\mathrm{X}$ matrix and the calculated yield as the $\mathrm{Y}$ vector. All data were auto scaled with 1 /standard deviation. Outliers were detected and removed based on influence, Hotelling $\mathrm{T}^{2}$ statistics and Qresiduals. Variables were excluded based on lowest regression coefficients and weighted regression coefficients. The models were calibrated using a full cross-validation, and evaluated based on the calibration root-mean-square error (RMSEC), and the cross-validation root-meansquare error (RMSECV). Principal Component Analysis (PCA) (Hotelling, 1933) was used for explorative data analysis and visualization of correlations between variables. The software Unscrambler X (Camo ASA, Oslo, Norway) was used for the multivariate data analysis.

\section{Results and discussion}

\subsection{Yield}

In this study, the weight after each processing step was followed for 60 salmon. This allows for knowledge on how processing influences each single fish and possibly identifying parameters relating the yield to the physical appearance of the salmon such as length, weight and thickness over the dorsal fin, or with calculated variables, such as the shape ratio, W/LT and K factor. Moreover, comparisons of belly cuts can aid in understanding how the slaughtering may affect the subsequent processing steps. Figure 2 presents the mass flow of the production with the calculated yield, the mean total weight, the mean weight of the left and right fillet, and the calculated loss after each processing step. 
156 Figure 2 illustrates the reduction in yield (including standard deviations) after each process step from an average of $76.7 \% \pm 6.5 \%$ after mechanical filleting (P1), to $67.5 \% \pm 7.2 \%$ after autotrimming (P2), and further down to $51.9 \% \pm 11.3 \%$ after manual trimming (P3). The trimming recipe determines how much is trimmed from the fillet and will therefore influence the resulting weight reduction. In this case study, approximately $50 \%$ of the gutted salmon could be sold as fillet. In comparison, Rørå et al. (1998) reported the yield of the untrimmed and trimmed fillets with skin to be $77.6 \%$ and $67.3 \%$, respectively. Nevertheless, Rørå et al. (2001) put the yield of farmed fish species in the range of $40-70 \%$. Hence, taken into consideration that the salmon in this study underwent deep skinning, a final fillet yield of $50 \%$ is regarded as consistent to what has been found by other researchers.

The weight loss during filleting was $23.3 \%$ on average. This comprises the removal of the skeletal frame as well as the head and tail. The auto-trimming loss accounted for $12.0 \%$ while during the manual trimming and deep skinning $23.1 \%$ was removed. In total the trimming loss amounts to $32.4 \%$. In comparison, Rørå et al. (1998) reported a filleting loss of $22.5 \%$ by mechanical filleting, and a trimming loss of $13.2 \%$. However, in their study the fillets were trimmed manually and the skin was not removed, which can explain the differences between the reported trimming losses of the two studies.

\subsection{Weight difference of fillets}

175

According to Figure 2 the mean weights and standard deviations of the fillets after P1 were $1710 \mathrm{~g}( \pm 147.1 \mathrm{~g})$ for the left side and $1733 \mathrm{~g}( \pm 150.2 \mathrm{~g})$ for the right side. A paired t-test showed that the observed difference was significant with a P value $<0.0001$. After P2 the mean weights (and standard deviations) of the left fillet was $1505 \mathrm{~g} \mathrm{(} \pm 124.5 \mathrm{~g}$ ) and the right fillet $1524 \mathrm{~g}( \pm 128.3 \mathrm{~g})$ and the paired t-test showed a significant difference with $\mathrm{P}=0.0006$. After the last trimming and skinning (P3) the mean weights and standard deviations of the left and right fillet were $1176 \mathrm{~g} \mathrm{(} \pm 112.9 \mathrm{~g}$ ) and $1213 \mathrm{~g}( \pm 108.5)$, respectively, with $\mathrm{P}=0.0085$. The $\mathrm{P}$ values increase after each processing step meaning that the fillets become more alike after each trimming. Hence the automatic trimming procedure trim the larger fillet more for the two fillets to become more alike, which in the worst case may result in over-trimming and thus increased loss.

Two data subsets were created for each of the three processing steps (P1-P3) in order to ensure that the weight differences between left and right fillet were significantly different from zero. One set containing the differences where the left fillet was larger than the right fillet, and another set for vice versa. A one-sample t-test was performed for each of the six data subsets, to test null-hypothesis that the means were equal to zero. The results are summarized in Table 2 with standard deviations (SD), number of samples in each group (n) and P values.

Table 2.

193 From Table 2 it can be seen that for nearly all data subsets the null-hypothesis can be rejected explained by the large standard deviation, that arises from a single data point being notably 
different from the others. This analysis suggests that the inspected fillet weight differences are significantly different from zero.

To ensure that the weight differences between all left and right fillets were not separated by a small margin, all fillets were divided into three groups: One group where the left fillets were larger than the right fillet by a certain margin, one group where the right fillets were larger than the left fillet by a certain margin, and finally a group were the left and right fillet differences were smaller than a certain margin. Two different margins were selected corresponding to the lower and upper bound of a 95\% confidence interval calculated for the absolute mean difference between all left and right fillet weights. This was chosen in order to encompass every possible mean difference based on the available data.

Table 3.

The number of samples in each of the three groups for all processing steps (P1-P3) is summarized in Table 3. The table shows a clear tendency of the right fillet being larger than the left. Even when considering the greater margin at the initial processing step, more than a third of the right fillets are larger than the left fillets.

In the present study, yield was calculated as (weight of left fillet + weight of right fillet)/gutted weight* $100 \%$, in contrast to other studies where yield has been calculated as ( $2 *$ fillet weight)/gutted weight*100\% (Rørå et al. 1998; Skjervold et al. 2001). In this study, it was shown that the weights of the two fillets differed significantly, and thus do the calculations here result in a more realistic and precise measure of yield compared to previous studies. Seen in the light of process analysis it is of paramount importance that the foundation for optimization is built on actual amounts in order to set up realistic goals for future production processes.

To identify at which step(s) during processing the weight difference was introduced the weight data were further examined. After P1, the right fillet was generally heavier than the left fillet except in 13 instances where the opposite was seen. After P2, 11 of the 13 incidences after P1, where the left fillet was heavier than the right fillet, was repeated. Additionally, two different salmons displayed a heavier left fillet summing up to a total of 13 incidences where left side fillet > right side fillet. After P3, 14 occurrences of the left fillets being larger than the right fillets were noted whereof nine of them were new, compared to the previous steps. Hence the weight differences after each process step did not necessarily coincide and the difference between the fillets after P2 and P3 seemed to be of less importance. Yet, it was the mechanical filleting that revealed the initial weight difference and the cause of this difference must therefore be a process prior to or during the mechanical filleting.

To trace back and investigate possible causes of the observed difference in weight between the right and left side fillet the belly cut and heading procedures were given a closer look.

Prior to the experiment it was hypothesized that the belly cut from the slaughtering process might influence the yield after filleting as an uneven cut would favour either the left or right side fillet, thus explaining the observed weight difference. Visual inspection of the belly cut in relation to the weight difference did not reveal any correlation. Nevertheless, the result of an ANOVA showed that the belly cut was the only significant variable related to the weight difference between the left and right fillet when performing the ANOVA on weight, length, thickness, degree of belly cut and $\mathrm{K}$ factor. This shows that extensive data acquisition and subsequent analysis can reveal correlations that are not caught by the human eye. 
Table 4.

The heading procedure was examined by investigating the images of the head cuts. It was observed that all heads had more meat/muscle on their left side compared to the right side. Hence, if this procedure were the only processing step causing the observed weight difference then we would expect that all the salmon would display a heavier right side fillet. More meat on the left side of the head should mean less meat on the left fillet and consequently a heavier right fillet. Although this was generally the case, a comparison of the weights revealed that $22 \%$ of the samples still exhibited a heavier left fillet compared to the corresponding right fillet. Consequently, the heading procedure cannot solely be responsible for the observed weight differences.

Factor analysis of how the measured and calculated variables (presented in Table 1) interact and influence the weight difference after each process step was performed. It showed that the weight difference after P2 solely depended on the weight difference after P1, and the weight difference after P3 did not correlate to any of the variables. These findings were expected since P2 and P3 both are influenced by predefined recipes, such as choice of trimming based on customer orders, and human factors during the manual trimming. The weight difference after P1, however, was most likely a result of the raw cut that separates the fillets from the skeletal frame. Consequently, it is only up to this processing step where prediction of yield is truly meaningful.

\subsection{Prediction of yield}

From the previous analyses presented in this study, indications were found that some parameters measured prior to processing influenced the yield after mechanical filleting. Building a prediction model for the yield after mechanical filleting, based on a combination of specific measurable pre-processing parameters, can provide an estimate of the yield even before the salmon has entered the processing facility. By providing the filleting company with these variables the yield after mechanical filleting for a certain batch can be estimated thus enabling better planning of the production by ordering (and assigning) the right batch to the right product category. This may assist the processing companies in obtaining the highest possible outcome from the incoming raw materials.

Several prediction models were built to predict the percentage yield after mechanical filleting based on the variables measured in this study. Initially, a model was built without excluding any variables and only by removing outliers. A total of 16 outliers were detected and removed (this will be discussed further in section 3.5) and both the RMSEC and RMSECV values of 0.47 and 0.60 , respectively, validated the model as being rather good. However, the model comprised all measured and calculated variables thus obscuring the outcome, which should contain variables that can be measured prior to processing in order to be truly applicable in the industry for predictive purposes. Hence the model was used as the basis for building three successive models, which were further analysed. These models are presented in Table 4. 
A PLS model (PLS1_1) was built on the seven variables listed in Table 4 remaining after a variable reduction. In total, 15 samples with outlying behaviour were removed from the dataset, which resulted in a RMSEC of 0.40 and a RMSECV of 0.43 for a five-factor model. Even though PLS1_1 showed very good prospect it was chosen to exclude the head weight from the variable selection, since ideally the variables included in the model should all be measurable prior to processing. Omitting the head weight and including all samples in the PLS1_2 model resulted in a total of 14 outliers, a RMSEC of 0.63 , and a RMSECV of 0.68 for a two-factor model.

The $\mathrm{K}$ factor is already measured at farm level by random sampling to determine the optimal time for harvesting, and again before and after slaughtering to direct products into the optimal product flow. The $\mathrm{K}$ factor comprises measurements of weight and length, both of which are used to construct some of the other variables. The thickness over the dorsal fin is the only necessary variable that is currently not registered. Therefore it was interesting to investigate the effect of excluding variables that contain the thickness as it results in a model that can be incorporated based on variables already measured in the production. PLS1_3was built on the complete data set and the $\mathrm{K}$ factor, length and weight. Leaving out the stand alone variable length from the model gave the best result and resulted in a total of 12 outliers, a RMSEC of 0.67, and a RMSECV of 0.71 for a two-factor model. Even though PLS1_3 gives a reasonable error of prediction, it is not the best model of the three presented in Table 4, and will thus not be investigated further.

Figure 3 depicts a score plot (a) and a correlation loading plot (b) of Factor-2 versus Factor-1 from the PLS1_2 model. Figure 3a depicts the scores of the samples. The samples are clustered depending on which slaughterhouse $(1,2$, or 3$)$ supplied them.

\section{Figure 3}

303 Figure $3 \mathrm{~b}$ show how the variables (shape ratio, length, W/LT, K factor, thickness and weight) correlate, as highly positive correlated variables have similar weights and will thus appear close together. Together the plots describe certain characteristics of the salmon depending on the supplying slaughterhouse. Salmon from slaughterhouse 1 overall were longer and had a higher shape ratio than samples from slaughterhouse 3. Samples from slaughterhouse 2 were characterised by being heavier in weight, thicker measured over the dorsal fin, and having a higher K factor compared to the two other slaughterhouses. The salmon from slaughterhouse 3 distinguished themselves by having lower values for all variables compared to the two other slaughterhouses. Although, all three groups overlap, the clustering of samples from slaughterhouse 2 and 3, respectively, is well defined. On the other hand, samples from slaughterhouse 1 span the whole plot with samples displaying the largest variation in both weight and W/LT index. This means that the variation in the raw material batch when buying salmon from either slaughterhouse 2 or 3 are more homogeneous and thereby easier for the production to handle while the width in batch variation of salmon from slaughterhouse 1 is bigger.

318 With PLS1_2 it is possible to predict the yield after filleting from only few measurable variables 319 with a RMSECV of 0.68 . The equation for this prediction model is given by the intercept and the beta coefficients together with the respective X loadings. The equation for PLS1_2 can be written as 
with $\mathrm{W}$ being the fish weight in grams, $\mathrm{L}$ the fish length in $\mathrm{cm}$, and $\mathrm{T}$ the thickness over the dorsal fin in $\mathrm{cm}$. The K-factor and shape ratio are both without units. The beta coefficients are all weighted, meaning that they describe how much they change when the predicted value changes one standard deviation. All beta coefficients (except Length) were significantly different from 0 with $\mathrm{P}$ values $<0.0001$. Length showed to be just on the limit with $\mathrm{P}=0.0731$.

By defining a common knowledge base for the salmon industry the processing companies can request that more parameters are measured prior to slaughtering, in this case the thickness. Such requests for particular parameters can be fed a model to determine the predicted yield of individual batches. Such a model can be incorporated as a decision support tool in the acquisition phase of the salmon allowing the processing company to define their demands when ordering raw materials from the farms. If knowledge transfer between the parties in the value chain should be facilitated the economical incitement to perform additional measurements must be present. In relation to the present study, we found that the thickness over the dorsal fin will provide the production companies with valuable information in the decision-making process. Ordering of raw materials that match the consumer requests for a specific trimming will ultimately reduce the loss of otherwise good meat and increase the profit of the filleting company. On the other hand, this additional information must also result in an increased price of raw material for the farm, as it is here the extra work is required. Therefore, further investigations must include the cost of adding an extra measurement at farm level in order to make a detailed prediction of the yield possible.

\subsection{Further Analysis of Deviating Samples}

We have demonstrated by PLS how the yield of the majority of the data (corresponding to 80\%) could be predicted with acceptable accuracy based on the available data. Hence these samples were assumed to be within a normal range with respect to the measured variables. With the aim of defining the processability of salmon the remaining $20 \%$ of the samples were further examined. This was achieved by investigating the differences of the 13 deviating samples, shared between the PLS1_2 model and the PCA model, to explore why the yield\% of these specific salmons could not be predicted.

No explanation was found with respect to origin of slaughterhouse or weight difference between the left and right fillets. Seven of the 13 deviation-duplicates originated from slaughterhouse 2 , four were supplied by slaughterhouse 1 , and two had come from slaughterhouse 3 . Ten of the 13 samples exhibited a heavier right fillet than left fillet. This is almost the same proportion, $75 \%$, as in the full dataset with $78 \%$.

In order to determine which variables could explain the variance in the deviation dataset, all variables were included in the analysis. Exploring the dataset with respect to all variables showed that fewer variables were needed to explain the variance. The performed PCA on the 13 deviating samples, and after variable reduction, resulted in three distinct PCs, which together contained $100 \%$ of the total variance. Figure 4 presents a bi-plot of the results with PC- 1 vs. PC2. The samples are circled to illustrate the clustering of the samples.

\section{Figure 4}


366 The bi-plot in Figure 4 reveals two groups of salmon in the deviation based dataset based on the

367 PCA model. The first group, marked with the left circle, characterised samples with a straight

368 belly cut (rank 0). The second group, marked with the right circle, represents samples that

369 display an angling of the belly cut to the left (rank 1 and 2). Figure 4 illustrates how the samples

370 cluster in relation to the loadings; samples to the right were salmon with higher values of length

371 and W/LT ratio compared to the cluster to the left. The left cluster, however, is dominated by

372 higher values of yield (P1) compared to the sample cluster to the right. Although the difference

373 in weight of the fillets cannot be fully explained by the belly cut, the angling of the cut on the

374 deviating samples seems to be correlated to the yield. The variance among the deviating

375 samples can be explained with fewer variables compared to the variance in the full dataset.

376 However, both the length and the W/LT ratio were negatively correlated to the yield and thus

377 may be two variables that should be investigated further. Knowledge of which factors that

378 relate to the yield may be used in a forward-looking way to optimize production and define new

379 requirements in the industry. Yet, the processing companies alone cannot achieve this. The

380 information flow in the value chain must be adapted to be able to handle requests from the

381 primary processing, or even further down the value chain. Despite the development within

382 traceability systems, the norm today is that no or only little information follows the fish, except

383 what is required by law, and hence will not be passed on to the next step in the value chain

384 (Frosch et al. 2008). This makes it difficult to optimize along the value chain, as information is

385 not shared between and over the processing links. Changing the information flow from the

386 traditional linear flow to a circular flow will enable all parties to share knowledge regarding the

387 raw materials. This can facilitate knowledge transfer between the links of the value chain, both

388 upstream and downstream, by directing the information to the part of the value chain that has

389 an influence on the specific share. Hence a question regarding measurements of new

390 parameters should be directed from the processing company to the farm, as it is here the

391 salmon are measured prior to determination of optimal harvest time.

392 Even if prediction of yield is made possible in the future the economic gain might not be enough

393 to lift the cost of the measurement. Another way to increase the outcome from the production

394 companies is to look at how to remove the additional meat from the heads. In this study we

395 found that all the salmon had more meat on the left side of the head after heading. This may be

396 explained by the positioning of the salmon during heading where the fish is placed on the left

397 side and as a result is resting on the surface when the cut is made. From the observations made

398 in the production the presence of additional meat on the head was always the case. Therefore, it

399 is not believed that resetting the equipment will recover the meat. More likely, it is the design of

400 the machine in which the salmon is placed flat on the left side that is responsible for a crooked

401 head cut with meat left on the head as a consequence. When the salmon is lying flat in the

402 heading machine the right side of the fish is stretched whereas the left side becomes more

403 compressed. This difference in positioning may cause a lopsided cut and meat is lost. Even if the

404 additional meat only amounts to 30-40 grams per fish $(\sim 1 \%)$ it adds up and for a 12000 tonnes

405 production, 73.5 tonnes extra salmon meat can be gained, amounting to $300.000 €$ /year.

406 Because of this, in addition to understanding how raw material variation influence the yield,

407 further analyses of productions and machinery must be made. In this context it is important to

408 stress that not all processing lines are identical and thus present results may not be applicable

409 to all companies. 
412 The production analysis conducted in this study focused on the three main processes: filleting, auto-trimming, and manual trimming. It was found that $78 \%$ of the salmon exhibited a weight difference between the fillets favouring the right side. Even though the heading procedure could explain part of the observed weight difference it does not explain it all as the belly cut also seems to influence the observed weight difference. Furthermore, the study revealed six variables; shape ratio, length, W/LT, thickness, weight and K factor, which together enabled an acceptable prediction of the filleting yield with a RMSECV of 0.68. Although the data set was small, and thus did not allow for testing of the predictive ability of the model on new data, the RMSECV show that it is possible to establish a relevant prediction model. The final prediction model was built on data from salmon of 4-5 kg harvested in January. Therefore, it must be investigated if different size groupings, seasonal differences and/or other variables influence the predictability of the yield. The beta coefficients in the model will change according to the size grouping and thus the model might need some adjustments with regards to raw materials from other seasons and/or origin.

Comprehensive data collection and analysis may at first seem a cumbersome method, yet the presented model could be used to give an estimate of the yield of a specific salmon batch before ordering the raw materials from the slaughterhouse. This will give the production company an advantage with respect to maintaining a healthy business. Additionally, the salmon farmer can follow the rearing of the fish more intensively with spot checks in the net pens, and by that find the optimal time of harvest based on the prediction model presented in this study.

We acknowledge the Danish AgriFish Agency for their financial support to the project "Follow the fish - Sustainable and optimal resource utilization in the Danish fish industry" (J. nr. 3400912-0469), and the project partners.

\section{References}

Chew, W. \& Sharratt, P. (2010). Trends in Process Analytical Technology. Analytical Methods, 2, 14121438.

Frosch, S., Randrup, M. \& Frederiksen, M.T. (2008). Opportunities for the Herring Industry to Optimize Operations Through Information Recording, Effective Traceability Systems, and Use of Advanced Data Analysis. Journal of Aquatic Food Product Technology, 17(4), 387-403.

Melberg, R. \& Davidrajuh R. (2009). Modelling Atlantic Salmon Fish Farming Industry. In IEEE International conference on Industrial Technology, ICIT, Gippsland, Australia.

Hotelling, H. (1933). Analysis of a Complex of Statistical Variables into Principal Components. Journal of Educational Psychology, 24(6 \& 7), 417-441 \& 498-520. 
Pomerantsev, A.L., \& Rodionova, O.Y. (2012). Process Analytical Technology: a Critical View of the Chemometricians. Journal of Chemometrics, 26, 299-310.

Powell, J., White, I., Guy, D., \& Brotherstone, S. (2008). Genetic Parameters of Production Traits in Atlantic Salmon (Salmo salar). Aquaculture, 274, 225-231.

Rahman, M.S. (2005). Dried Food Properties: Challenges Ahead. Drying Technology: An International Journal, 23(4), 695-715.

Rørå, A.M, Lvåle, A., Mørkøre, T., Rørvik, K-A., Steien, S.H., \& Thomassen, M.S. (1998). Process Yield, Colour and Sensory Quality of Smoked Atlantic Salmon (Salmo salar) in Relation to Raw Material Characteristics. Food Research International, 31(8), 601-609.

Rørå, A.M., Mørkøre, T., \& Einen, O. (2001). Primary Processing (Evisceration and Filleting). In Kestin, S.C. \& Warriss, P.D. (Eds.). Farmed Fish Quality (pp. 249-260), Blackwell Science.

Regulation (EU) No 1151/2012 OF THE EUROPEAN PARLIAMENT AND OF THE COUNCIL on quality schemes for agricultural products and foodstuffs. https://www.gov.uk/government/uploads/system/uploads/attachment data/file/388544/lond on-cure-smoked-scottish-salmon-spec.pdf. Accessed 07.09.2015.

Searchinger, T., Hanson, C., Ranganathan, J., Lipinski, B., Waite, R., Winterbottom, R., Dinshaw, A. \& Heimlich, R. (2013). Creating a Sustainable Food Future. A menu of solutions to sustainably feed more than 9 billion people by 2050. World Resources Report 2013-2014: Interim Findings.

Skjervold, P.O., Rørå, A.M., Fjæra, S.O., Vegusdal, A., Vorre, A., \& Einen. O. (2001). Effects of Pre-, In-, or Post-rigor Filleting of Live Chilled Atlantic Salmon. Aquaculture, 194, 315-326.

Somsen, D., Capelle, A. \& Tramper, J. (2004). Production Yield Analysis in the Poultry Processing Industry. Journal of Food Engineering, 65, 479-487.

van den Berg, F., Lyndgaard, C.B., Sørensen, K.M. \& Engelsen, S.B. (2013). Process Analytical Technology in the Food Industry. Trends in Food Science \& Technology, 31, 27-35.

Wold, H. (1975). Path Models with Latent Variables: The NIPALS approach. In H.M. Blalock, A. Aganbegian, F.M. Borodkin, R. Boudon, \& V. Cappecchi (Eds.), Quantitative Sociology: International perspectives on mathematical and statistical modelling, pp. 307-357. New York: Academic Press. 

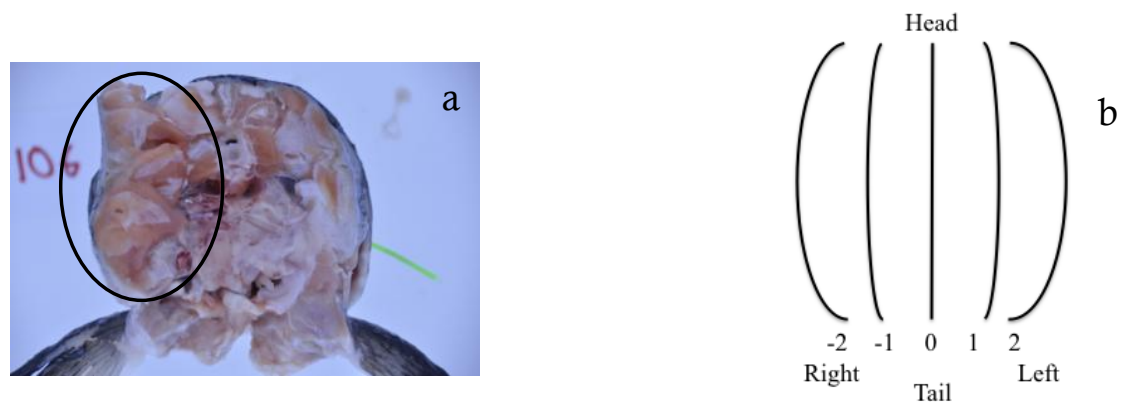

Figure 1 Evaluation of heads and belly cut. Figure 1a depicts the presence of additional meat on the left side of the head marked by a circle. Figure $1 \mathrm{~b}$ show a schematic drawing of the angle of the belly cut. Cuts angling to the right are denoted -2 and -1 , straight cuts are 0 and cuts angling to the left 1 and 2. 


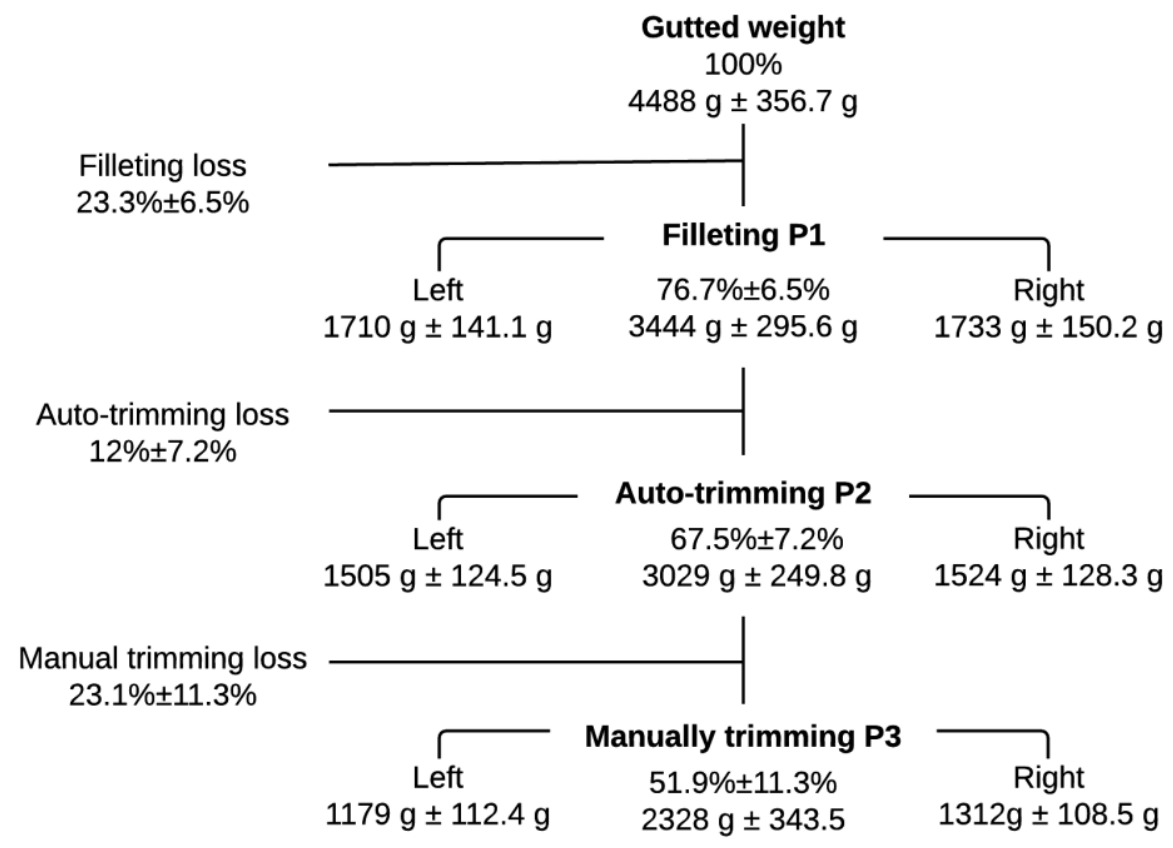

Figure 2 Mass flow of the production of salmon fillets. Presentation of mean weight, percentage yields and loss after each processing step together with the mean weight of the left and right fillets $(n=60)$. 

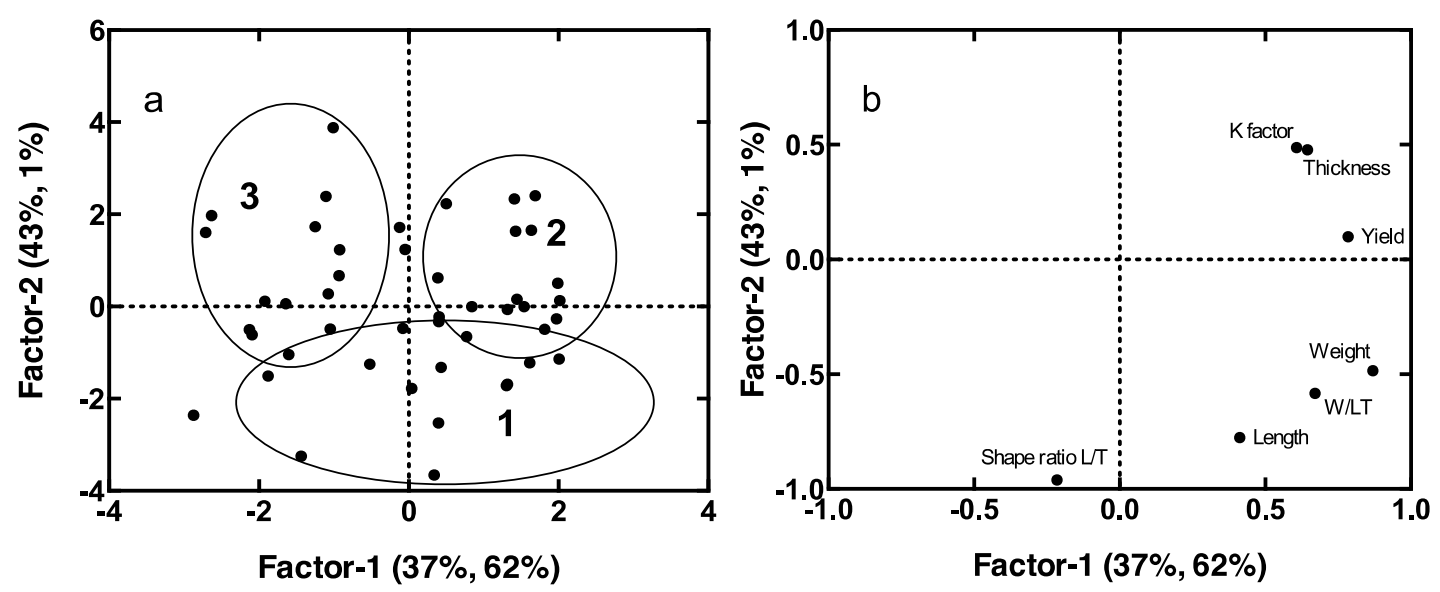

Figure 3 Partial Least Squares (PLS) regression. Plots showing the final model PLS1_2 with six variables related to the physical appearance of the salmon prior to filleting. The scores plot (a) shows the clustering of the samples according to slaughterhouse (1, 2 or 3 ) highlighted with circles. The correlation loading plot (b) show how the variables correlate. Both plots show the maximum variation of the dataset after outliers have been removed. 


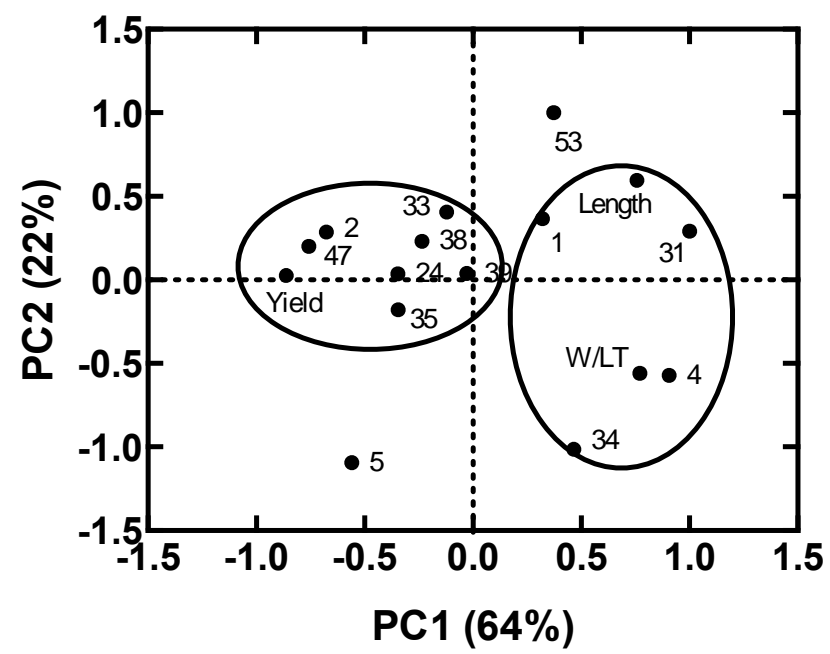

Figure 4 Principal Component Analysis (PCA) of outlier samples. Bi-plot of outlier samples together with the variables (yield, length and W/LT). The plot shows two sample clusters related to the loadings. The two clusters are highlighted with circles, the left being samples with a straight belly cut and the right being samples with an angled belly cut. The plot shows the maximum variation of the dataset. PC-1 accounts for $64 \%$ of the variation in the dataset. PC- 2 accounts for $22 \%$ of the variation. 
Figure captions

Figure 1 Evaluation of heads and belly cut. Figure 1a depicts the presence of additional meat on the left side of the head marked by a circle. Figure $1 \mathrm{~b}$ show a schematic drawing of the angle of the belly cut. Cuts angling to the right are denoted -2 and -1 , straight cuts are 0 and cuts angling to the left 1 and 2.

Figure 2 Mass flow of the production of salmon fillets. Presentation of mean weight, percentage yields and loss after each processing step together with the mean weight of the left and right fillets $(n=60)$.

Figure 3 Partial Least Squares (PLS) regression. Plots showing the final model PLS1_2 with six variables related to the physical appearance of the salmon prior to filleting. The scores plot (a) shows the clustering of the samples according to slaughterhouse (1, 2 or 3$)$ highlighted with circles. The correlation loading plot (b) show how the variables correlate. Both plots show the maximum variation of the dataset after outliers have been removed.

Figure 4 Principal Component Analysis (PCA) of outlier samples. Bi-plot of outlier samples together with the variables (yield, length and $\mathrm{W} / \mathrm{LT}$ ). The plot shows two sample clusters related to the loadings. The two clusters are highlighted with circles, the left being samples with a straight belly cut and the right being samples with an angled belly cut. The plot shows the maximum variation of the dataset. PC- 1 accounts for $64 \%$ of the variation in the dataset. PC- 2 accounts for $22 \%$ of the variation. 
Table 1 Variable definition. Table presenting the calculated variables together with their definitions with $\mathrm{W}$ being the weight, $\mathrm{L}$ the length and $\mathrm{T}$ the thickness of each fish.

\begin{tabular}{|ll|}
\hline Calculated variables & Definition \\
\hline Shape ratio $(\mathbf{L} / \mathrm{T})$ & Length-to-thickness ratio \\
\hline $\mathbf{W} / \mathbf{L}^{2}$ & Weight divided by the squared length \\
\hline $\mathbf{L}^{3} / \mathbf{W T}$ & $\begin{array}{l}\text { The cubed length divided by the weight and } \\
\text { length }\end{array}$ \\
\hline $\mathbf{W} / \mathbf{L T}$ & Weight divided by length and thickness \\
\hline $\mathbf{K}$ factor $\left(\mathbf{W} / \mathbf{L}^{3}\right)$ & Weight divided by the cubed length \\
\hline
\end{tabular}


Table 2 Weight differences. Presentation of the results from a one-sample t-test on the cases where right $>$ left and right<left for each process step (P1-P3). The results are provided as weight difference (g) together with standard deviation (SD), number of samples (n) and P values.

\begin{tabular}{|c|c|c|c|}
\hline & P1 & P2 & P3 \\
\hline $\begin{array}{l}\text { Weight } \\
\text { difference }(\mathrm{g}) \\
\text { right }>\text { left }\end{array}$ & $\begin{array}{l}36.2 \\
(\mathrm{SD}=20.3, \mathrm{n}=47) \\
\mathrm{P} \text { value }=4.8511 \mathrm{e}-16\end{array}$ & $\begin{array}{l}31.7 \\
(\mathrm{SD}=15.7, \mathrm{n}=47) \\
\mathrm{P} \text { value }=5.6827 \mathrm{e}-18\end{array}$ & $\begin{array}{l}73.4 \\
(\mathrm{SD}=58.2, \mathrm{n}=43) \\
\mathrm{P} \text { value }=2.3965 \mathrm{e}-10\end{array}$ \\
\hline $\begin{array}{l}\text { Weight } \\
\text { difference }(\mathrm{g}) \\
\text { right }<\text { left }\end{array}$ & $\begin{array}{l}23.8 \\
(S D=19.7, n=13) \\
P \text { value }=9.2100 \mathrm{e}-04\end{array}$ & $\begin{array}{l}30.0 \\
(\mathrm{SD}=57.1, \mathrm{n}=13) \\
\mathrm{P} \text { value }=0.0821\end{array}$ & $\begin{array}{l}87.8 \\
(S D=75.4, n=14) \\
P \text { value }=7.7666 \mathrm{e}-04\end{array}$ \\
\hline
\end{tabular}


Table 3 Number of cases where the difference between left and right fillet exceeds a certain margin. For each processing step (P1-P3), each fish is divided into one of three groups, depending on whether the difference between left and right fillet exceeds a certain margin or not. The margins correspond to the bounds of a $95 \%$ confidence interval calculated on the absolute mean differences between all fillets.

\begin{tabular}{|l|c|c|c|c|c|c|}
\hline & \multicolumn{2}{|c|}{ P1 } & \multicolumn{2}{c|}{ P2 } & \multicolumn{2}{c|}{ P3 } \\
\hline Margin, M & $28.2 \mathrm{~g}$ & $38.8 \mathrm{~g}$ & $23.8 \mathrm{~g}$ & & \\
\hline $\begin{array}{l}\text { No. of fish } \\
\text { where } \\
\text { left fillet is } \\
\text { larger right } \\
\text { by M }\end{array}$ & 4 & 2 & 3 & 1 & 7 & $5 \mathrm{~g}$ \\
\hline $\begin{array}{l}\text { No. of fish } \\
\text { where the } \\
\text { difference } \\
\text { between left } \\
\text { and right } \\
\text { fillet are } \\
\text { smaller than } \\
\text { M }\end{array}$ & 25 & 36 & 26 & 42 & 32 & 38 \\
\hline $\begin{array}{l}\text { No. of fillets } \\
\text { where } \\
\text { left < right } \\
\text { by M }\end{array}$ & 31 & 22 & 31 & 17 & & \\
\hline
\end{tabular}


Table 4 Prediction models. The table presents three PLS models and the resulting Root Mean Square Error of Calibration (RMSEC), Root Mean Square Error Cross Validated (RMSECV), number of factors, and the number of outliers.

\begin{tabular}{|l|l|l|l|l|l|}
\hline Model & Variables & RMSEC \%yield & RMSECV \%yield & \# Factors & Outliers \\
\hline PLS1_1 & $\begin{array}{l}\text { Shape ratio } \\
\text { Length, L } \\
\text { Head weight } \\
\text { W/LT } \\
\text { Thickness, T } \\
\text { K factor } \\
\text { Weight, W }\end{array}$ & 0.40 & 0.43 & 5 & 15 \\
\hline PLS1_2 & $\begin{array}{l}\text { Shape ratio } \\
\text { Length, L } \\
\text { W/LT } \\
\text { Thickness, T } \\
\text { K factor } \\
\text { Weight, W }\end{array}$ & 0.63 & 0.68 & 2 & 14 \\
\hline PLS1_3 & $\begin{array}{l}\text { K factor } \\
\text { Weight, W }\end{array}$ & 0.67 & & & \\
\hline
\end{tabular}


Table captions

Table 1 Variable definition. Table presenting the calculated variables together with their definitions with $\mathrm{W}$ being the weight, $\mathrm{L}$ the length and $\mathrm{T}$ the thickness of each fish.

Table 2 Weight differences between left and right side fillet. Presentation of the results from a one-sample t-test on the cases where right side fillet $>$ left side fillet and right side fillet $<$ left side fillet for each process step (P1-P3). The results are provided as weight difference (g) together with standard deviation (SD), number of samples (n) and $\mathrm{P}$ values.

Table 3 Number of cases where the difference between left and right fillet exceeds a certain margin. For each processing step (P1-P3), each fish is divided into one of three groups, depending on whether the difference between left and right fillet exceeds a certain margin or not. The margins correspond to the bounds of a $95 \%$ confidence interval calculated on the absolute mean differences between all fillets.

Table 4 Prediction models. The table presents three PLS models and the resulting Root Mean Square Error of Calibration (RMSEC), Root Mean Square Error Cross Validated (RMSECV), number of factors, and the number of outliers. 
Supplementary Interactive Plot Data (CSV)
Click here to download Supplementary Interactive Plot Data (CSV): Suplementary data.cs

Supplementary Interactive Plot Data (CSV)
Click here to download Supplementary Interactive Plot Data (CSV): Suplementary data.csv

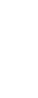

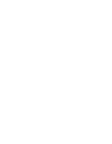

(1)

$\sqrt{2}$

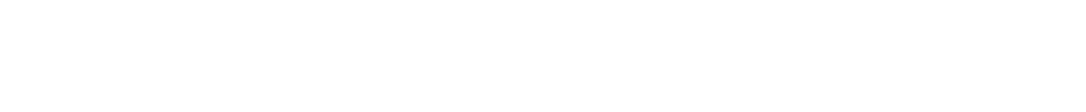

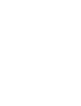
(1) (1) (1) (2) (2) (1) (2) (2) (2) (2) (n) 政 (n) 更 (n) (1) (1) (1) (1) (1) (1) (1) (1) (1) (1)

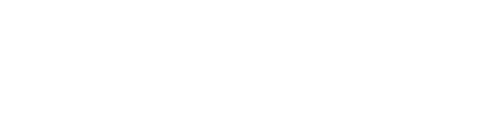
(1) (1) 